\title{
PARAMETRICAL METHOD FOR DETERMINING OPTIMAL SHIP CARRYING CAPACITY AND PERFORMANCE OF HANDLING EQUIPMENT
}

Jan P. Michalski, Assoc. Prof.

Gdańsk University of Technology, Poland

\begin{abstract}
The paper presents a method of evaluating the optimal value of the cargo ships deadweight and the coupled optimal value of cargo handling capacity. The method may be useful at the stage of establishing the main owners requirements concerning the ship design parameters as well as for choosing a proper second hand ship for a given transportation task. The deadweight and the capacity are determined on the basis of a selected economic measure of the transport effectiveness of ship - the Required Freight Rate. The mathematical model of the problem is of a deterministic character and the simplifying assumptions are justified for ships operating in the liner trade. The assumptions are so selected that solution of the problem is obtained in analytical closed form. The presented method can be useful for application in the preliminary ship design or in the simulation of pre-investment transportation task studies.
\end{abstract}

Keywords: ship design; deadweight and cargo handling optimization; required freight rate

\section{INTRODUCTION}

Methodology of engineering design with extreme of selected function includes both a general formulation of the problem, eg. [1], [2], as well as considerations relating to the selected technical objects, such as ships [3] $\div$ [8]. The area of research in this field are aspects such as criterial measurement assessment values of the ship, defining areas of feasible solutions or algorithms for optimal solutions. The ship-owner - investor making an investment decision - ordering the construction of the ship, or buying a ship expects an optimal object in the sense important for him. Determining the parameters of such a ship, guided only by intuition and experience does not always lead to the correct choice, as aptness depends on future market conditions in shipping (prices, costs, inflation) [9], which forecasts are subject to uncertainty.

To make the right investment decisions calculation methods to simulate future market conditions and the projected effects of technical and economic can be helpful. In the case of cargo ships such issue can be described by a mathematical model, and the simulated results may provide grounds for making an investment decision. As an example, the method can be used [10] $\div$ [13] for a preliminary ship design parameters optimal in the sense of, respectively, minimizing the cost of construction of the hull, fuel consumption, or the lowest freight rate providing the required return on investment.
Parametric studies done with the method described in [12] indicate a significant correlation of optimal carrying capacity of the ship from the efficiency of reloading equipment, on which depends the time the ship is in port intended for loading and unloading. The method presented in the article allows to investigate the relationship between the optimum load capacity of the ship and optimum performance of handling equipment - making the cost of handling dependant of the performance of the handling, and thus from the time of handling, which express the accepted method of analytical relationships. The approach is a generalization of the method described in [12], where the optimum load capacity of the vessel, minimizing the required rate of freight RFR (Required Freight Rate), were determined by arbitrarily ingested handling performance $\mathrm{Q}$ and the assumed rate of $\mathrm{W}_{\mathrm{j}}$ for handling a cargo unit.

The presented method extends the range of optimization parameters of the designed ship; has both cognitive value, as illustrated by the results presented preliminary parametric studies and the resulting general conclusions and utilitarian value, which is reflected in the attached solution design task example.

\section{STATEMENT OF THE PROBLEM AND OBJECTIVES}

The subject of the research is to develop a mathematical model of the method for determining the capacity Pn of cargo 
ships and productivity Q of handling equipment - optimal in terms of minimizing the required freight rate RFR for the transport of cargo. It is assumed that both the handling and the unit cost of handling depend on the performance of the $\mathrm{Q}$ handling equipment. The relationship $\mathrm{W}_{\mathrm{J}}=\mathrm{W}_{\mathrm{J}}(\mathrm{Q})$ means a fee for handling unit load with devices of $Q$ capacity.

The issue is described by the collection of the following relationship:

$$
R F R=R F R(P n, Q, \bar{x})
$$

$$
\left\{\begin{array}{l}
\frac{\partial R F R\left(P n, Q, W_{J}(Q), \bar{x}\right)}{\partial P n}=0 \longrightarrow P n_{o p t}=f\left(W_{J}(Q), \bar{x}\right) \\
\frac{\partial R F R\left(P n, Q, W_{J}(Q), \bar{x}\right)}{\partial Q}=0 \longrightarrow Q_{o p t}=f\left(W_{J}(Q), \bar{x}\right)^{(2)}
\end{array}\right.
$$

Accepted labels of vector method parameters $\bar{x}$ have the following interpretation:

Pn - dead-weight tonnage;

$\mathrm{Q}$ - performance of handling equipment;

$\mathrm{W}_{\mathrm{J}}$ - unit cost of loading and unloading;

$\bar{x}$ - vector of other parameters describing the issue considered;

$v$ - operational speed;

$\mathrm{R}$ - the length of the cruise route;

$\mathrm{C}_{\mathrm{J}}$ - the unit cost of fuel;

$\mathrm{C}_{\mathrm{A}}$ - Admiralty factor;

$\mathrm{C}_{\mathrm{H}}$ - the coefficient of cost to performance handling proportionality;

$\mathrm{G}_{\mathrm{J}}$ - unit fuel consumption;

$\mathrm{T}_{\mathrm{M}}$ - time route in one cruise;

$\mathrm{T}_{\mathrm{Q}}$ - total time of loading and unloading in one cruise;

$\mathrm{T}_{\mathrm{O}}$ - waiting time on the roadster and in the port;

$\mathrm{Z}$ - weight of supplies;

$\mathrm{Z}_{\mathrm{H}}$ - the number of days of operation of the ship during the year;

A - the rate of annual depreciation;

i - average annual rate of inflation;

$\mathrm{m}$ - the number of years of the ship operation;

$\mathrm{n}$ number of voyages per year;

$r$ - required rate of return of investment;

$\mathrm{t}$ - tax rate;

$\varepsilon-\quad$ the average capacity utilization rate of the ship;

$\lambda$ - the average rate of carrying capacity utilization of the ship;

$\eta-\quad$ ship displacements utilization factor;

$\mu-\quad$ ratio of annual maintenance costs.

\section{MATHEMATICAL MODEL OF THE ISSUE}

As far as criterial measurement for evaluating the values of the designed ship, expressing its economic and technical effectiveness as in [3] $\div$ [6] or in [9] $\div$ [12], the minimum required rate of freight RFR has been adopted. The rate of RFR is the lowest rate of freight ensuring a fixed rate of return on investment, at incurred capital costs and operating and other parameters of the problem.
The adoption of the minimum rate of RFR as a measure of evaluation criterion values of the ship is justified by the fact that the future of real market conditions and freight rates, the highest yield is obtained with the smallest ship of the required freight rate [3], [5], [8]. If the future actual freight rates prove to be higher than the minimum freight rate RFR, the actual rate of return will be higher than the rate assumed. When future freight rates are lower than the rate of RFR, then the investment will not provide the assumed profitability.

It was assumed that the cost of construction (or purchase) of a cargo ship with a fixed speed depends mainly on the capacity Pn and grows slower than a linear function [8], [12]; therefore the cost of investment J can be approximated by a simplification of equation:

$$
J=K_{J} \cdot P n^{2 / 3}
$$

where the proportionality coefficient $\mathrm{K}_{\mathrm{J}}$ is determined on the basis of price $\mathrm{J}_{\mathrm{O}}$ and capacity $\mathrm{Pn}_{\mathrm{o}}$ of the ship like:

$$
K_{J}=J_{o} \cdot P n_{o}^{-2 / 3}
$$

Annual operating expenses of a ship AOC (Annual Operating Cost), which depend on the capacity of the ship, relate mainly to the cost of fuel consumed and the cost of cargo handling operations. The average annual cost of lubricating oil and repair factor expressed as $\mu>1$ take into account the increasing cost of fuel. Associated with the drive annual operating costs AOC of the vessel making during the year $n$ cruises, with the time of the route $T_{M}$, are:

$$
A O C=n \cdot T_{M} \cdot \mu \cdot C_{j} \cdot G_{j} \cdot N e
$$

Expressing propulsion power Ne with admiralty equation, where $\mathrm{D}$ is the displacement of the ship, and $\mathrm{C}_{\mathrm{A}}$ is the ration of the Admiralty, a relationship is obtained:

$$
A O C=\mu \cdot n \cdot T_{M} \cdot C_{j} \cdot G_{j} \cdot \frac{D^{2 / 3} \cdot v^{3}}{C_{A}}=\mu \cdot n \cdot T_{M} \cdot C_{j} \cdot G_{j} \cdot\left[\left(\frac{\varepsilon \cdot \lambda \cdot P n}{\eta}\right)^{2 / 3} \cdot \frac{v^{3}}{C_{A}}\right]=K c \cdot n \cdot P n^{2 / 3}
$$

presuming designation:

$$
K c=\frac{\mu \cdot C_{J} \cdot G_{J} \cdot v^{2} \cdot R}{C_{A}} \cdot\left(\frac{\varepsilon \cdot \lambda}{\eta}\right)^{2 / 3}
$$

Capacity utilization rates and displacements are defined by the relationship:

$$
\lambda=\frac{P n-Z}{P n}=\text { const } \quad \eta=\frac{P n}{D}=\text { const }
$$

where $\mathrm{Z}$ is the mass of supplies (fuel) consumed in one cruise.

Loading and unloading time has a significant impact on the efficiency of maritime transport. The size of income for freight depends on the quantity of goods carried - increases with: load capacity and speed of the ship, shortening time handling thanks to load handling devices of increasing productivity, for which the fee is charged adequately. It is assumed that the unit 
cost $\mathrm{W}_{\mathrm{J}}$ for handling unit load is directly proportional to the efficiency of the $\mathrm{Q}$ handling equipment, and the performance of ballast system provides secure vessel reloading.

The value of empirically specific proportionality factor $\mathrm{C}_{\mathrm{H}}=\mathrm{W}_{\mathrm{J}} / \mathrm{Q}$ depends on local market conditions in the ports of the considered shipping line.

The costs of handling by port facilities (loading and unloading) AHC (Annual Handling Cost) depends on the weight of the load, the number of trips a year $n$, and the unit charge $\mathrm{W}_{\mathrm{J}}$, dependent on performance $\mathrm{Q}$ :

$$
W_{J}=C_{H} \cdot Q
$$

Under this assumption the annual cost of handling is:

$$
A H C=n \cdot(2 \cdot \varepsilon \cdot \lambda \cdot P n) \cdot W_{J}=2 \cdot \varepsilon \cdot \lambda \cdot n \cdot C_{H} \cdot Q \cdot P n=K h \cdot n \cdot Q \cdot P n
$$

where the factor Kh means:

$$
K h=2 \cdot \varepsilon \cdot \lambda \cdot C_{H}
$$

The time of one cruise $\mathrm{T}$ consists of a rout time $\mathrm{T}_{\mathrm{M}}$, waiting time on the roadstead and in the port $\mathrm{T}_{\mathrm{O}}$, and from the time of loading and unloading $\mathrm{T}_{\mathrm{Q}}$, the total capacity of handling equipment is $\mathrm{Q}$ :

$$
T=T_{M}+T_{o}+T_{Q}=\frac{R}{v}+T_{o}+2 \cdot \frac{\varepsilon \cdot \lambda \cdot P n}{Q}
$$

The number of cruises $n$ made during the year by the ship depends on the time $Z_{H}$ of operation of the vessel during the year and one cruise time $\mathrm{T}$ on the route with a range of $\mathrm{R}$ :

$$
n=\frac{Z_{H}}{T}=\frac{Z_{H}}{\frac{R}{v}+T_{o}+2 \cdot \frac{\varepsilon \cdot \lambda \cdot P n}{Q}}=\frac{K q \cdot Q}{K r \cdot Q+K p \cdot P n}
$$

Adopted auxiliary variables mean:

$$
K q=Z_{H} \cdot v \quad K r=R+T_{o} \cdot v \quad K p=2 \cdot \varepsilon \cdot \lambda \cdot v
$$

The annual capacity of the vessel (ACC Annual Cargo Capacity) is:

$$
A C C=n \cdot \varepsilon \cdot \lambda \cdot P n
$$

After taking into account the depreciation of the ship A and a rate of inflation $i$ and tax and interest rate $t$, discounted balance of the financial cost of the investment and ongoing $m$ years of operation of the ship with an initial investment cost $\mathrm{J}$ is expressed by the relationship:

$$
\frac{A A C}{\operatorname{CRFT}(r, m, i, t)}=J+\frac{A O C+A H C+A}{C R F T(r, m, i, t)}
$$

The coefficient of return of capital after tax CRFT (Capital Recovery Factor after Tax) is defined by the relationship:

$$
\operatorname{CRFT}(r, m, i, t)=\frac{(r+i+r \cdot i)}{1-(1+r+i+r \cdot i)^{-m} \cdot(1-t)}
$$

The annual allocations of linear depreciation loss of value of the vessel are:

$$
A=\frac{J}{m}=\frac{K_{J} \cdot P n^{2 / 3}}{m}
$$

The discounted annual costs AAC (Annual Average Costs) are:

$$
A A C(P n, Q)=J(P n) \cdot C R F T(r, m, i, t)+A O C(P n)+A H C\left(P n, Q, W_{J}\right)+A(P n, m)
$$

\section{OPTIMAL CAPACITY AND PERFORMANCE OF HANDLING EQUIPMENT}

Freight rate bringing income to cover costs within $m$ years of operation of the ship, at the required rate of return of investment $r, t$ tax rate, defines the minimum wage requirement $R F R$. The rate is the ratio of annual income for freight AAC to the annual capacity of the ship ACC:

$R F R(P n, Q, \bar{x})=\frac{A A C}{A C C}=\frac{J \cdot C R F T+A O C+A H C+A}{A C C}=\frac{P n^{-1 / 3}}{\varepsilon \cdot \lambda} \cdot\left(\frac{K_{J} \cdot\left(C R F T+m^{-1}\right) \cdot(K r \cdot Q+K p \cdot P n)}{K q \cdot Q}+K c\right)+\frac{K h \cdot Q}{\varepsilon \cdot \lambda}$

The stationary point of function RFR - defined from the necessary condition of the existence of extreme - is the solution of equations in relation to its unknowns $\mathrm{Q}$ and $\mathrm{PN}$ :

$$
\begin{gathered}
\frac{\partial R F R\left(P n, Q, W_{J}(Q), \bar{x}\right)}{\partial Q}=\frac{\partial}{\partial Q}\left[\frac{P n^{-1 / 3}}{\varepsilon \cdot \lambda} \cdot\left(\frac{K_{J} \cdot\left(C R F T+m^{-1}\right) \cdot(K r \cdot Q+K p \cdot P n)}{Z_{H} \cdot v \cdot Q}+K c\right)+2 \cdot C_{H} \cdot Q\right]= \\
=\frac{\partial}{\partial Q}\left(\frac{2 \cdot P n^{2 / 3} \cdot K_{J} \cdot\left(C R F T+m^{-1}\right)}{Z_{H} \cdot Q}+2 \cdot C_{H} \cdot Q\right)=-\frac{2 \cdot P n^{2 / 3} \cdot K_{J} \cdot\left(C R F T+m^{-1}\right)}{Z_{H} \cdot Q^{2}}+2 \cdot C_{H}=0
\end{gathered}
$$

$$
\begin{gathered}
\frac{\partial R F R\left(P n, Q, W_{J}(Q), \bar{x}\right)}{\partial P n}=\frac{\partial}{\partial P n}\left[\frac{P n^{-1 / 3}}{\varepsilon \cdot \lambda} \cdot\left(\frac{K_{J} \cdot\left(C R F T+m^{-1}\right) \cdot(K r \cdot Q+K p \cdot P n)}{Z_{H} \cdot v \cdot Q}+K c\right)+2 \cdot C_{H} \cdot Q\right]= \\
=\frac{-1}{3} \frac{P n^{-4 / 3}}{\varepsilon \cdot \lambda} \cdot\left(\frac{K j \cdot\left(C R F T+m^{-1}\right) \cdot(K r \cdot Q+K p \cdot P n)}{K q \cdot Q}+K c\right)+\frac{P n^{-1 / 3}}{\varepsilon \cdot \lambda} \frac{K j \cdot\left(C R F T+m^{-1}\right) \cdot K p}{K q \cdot Q}=0
\end{gathered}
$$

After transformation and organizing expressions, the determined unknowns represent the optimal values that can be expressed explicite by method parameters:

$P n_{o p t}=\left(\frac{K_{J} \cdot C R F T \cdot\left(1+m^{-1}\right)}{Z_{H} \cdot C_{H}}\right)^{3 / 4} \cdot\left[\frac{1}{4 \cdot \varepsilon \cdot \lambda \cdot v} \cdot\left(R+T_{o} \cdot v+\frac{\mu \cdot C_{J} \cdot G_{J} \cdot v^{3} \cdot R \cdot(\varepsilon \cdot \lambda)^{2 / 3} \cdot Z_{H}}{K_{J} \cdot C_{A} \cdot \eta^{2 / 3} \cdot C R F T \cdot\left(1+m^{-1}\right)}\right)\right]^{3 / 2}$

$Q_{o p t}=\left(\frac{K_{J} \cdot C R F T \cdot\left(1+m^{-1}\right)}{Z_{H} \cdot C_{H}}\right)^{3 / 4} \cdot\left[\frac{1}{4 \cdot \varepsilon \cdot \lambda \cdot v} \cdot\left(R+T_{o} \cdot v+\frac{\mu \cdot C_{J} \cdot G_{J} \cdot v^{3} \cdot R \cdot(\varepsilon \cdot \lambda)^{2 / 3} \cdot Z_{H}}{K_{J} \cdot C_{A} \cdot \eta^{2 / 3} \cdot C R F T \cdot\left(1+m^{-1}\right)}\right)\right]^{1 / 2}$ 


\section{EXAMPLE OF METHOD APPLICATION}

Selected application results of the method illustrate its applicability in relation to the tasks of design and investment - determining the optimum capacity of the designed ship $\mathrm{Pn}_{\mathrm{opt}}$ and coupled to the efficiency of handling equipment $\mathrm{Q}_{\text {opt }}$ (binding the cost with handling time) - as to minimize the rate of freight RFR, and in particular concern:

- Identification of significant parameters of the model;

- And example of a solution to a design task;

- Parametric studies of relationship RFR, $\mathrm{Pn}_{\mathrm{opt}}$ and $\mathrm{Q}_{\mathrm{opt}}$ to the length of the line $\mathrm{R}$ and the value factor $\mathrm{C}_{\mathrm{H}}$.

Technical and economic parameters of the model adopted in the presented results are given in the table describing the design task.

\section{The essential method parameters.}

Tests of parametric sensitivity of the model to change of its parameters performed show that a significant impact on the value determined parameters $\mathrm{Pn}_{\mathrm{opt}}$ and $\mathrm{Q}_{\mathrm{opt}}$, as well as to minimize the rate of freight RFR has the length of the route voyage $R$ and the time TQ and unit cost of handling $W_{\text {, }}$, which depend on the efficiency of handling $\mathrm{Q}$ determined by coefficient of proportionality $\mathrm{C}_{\mathrm{H}}$. The model shows a lower sensitivity to both change in the ship's speed $v$, and the change in the price of fuel $\mathrm{C}_{i}$.

This result stems from a significant relationship of cruise route time (bringing freight income), dependent on the length of the cruise route, until handling (non-profit stop of the ship), which depends on the capacity of handling equipment and vessel capacity.

\section{An example of a solution to the design task.}

One should appoint an optimum load-bearing capacity of the ship, optimum performance of handling equipment, and the minimum rate of the projected freight ship, with service speed $\mathrm{v}=18 \mathrm{kn}$, intended for line Gdańsk-Rio de Janeiro of route length of $\mathrm{R}=5930 \mathrm{NM}$, accepting the empirical factor $C_{H}=\frac{W_{j}[\mathrm{~S} / \mathrm{t}]}{Q[\mathrm{t} / \mathrm{h}]}=0,15 \frac{[\mathrm{S} / \mathrm{t}]}{[\mathrm{th}]}$. The values of other parameters of the tasks are contained in the table Tab. 1.

\section{Selected parametric study.}

The results of research on the impact of the coefficient $\mathrm{C}_{\mathrm{H}}$ expressing the proportionality of the cost-efficiency of handling, for example, a ship with a given velocity $\mathrm{v}=15 \mathrm{kn}$, the length of the shipping line, respectively $\mathrm{R} 1=2000 \mathrm{NM}$ and $\mathrm{R} 2=5000 \mathrm{NM}$, and other parameters, such as in the example design task are presented. The results are shown on graphs in Fig. 1, which illustrate the characteristics and performance of the optimum load handling equipment when changing the proportionality factor handling cost performance to (time) handling.

\section{Prospects for implementation of further research.}

Multi-dimensional vector of technical and economic parameters of the method allows to conduct parametric studies that may be of interest both in the design of shipowners investment, as well as in solving ships design issues.

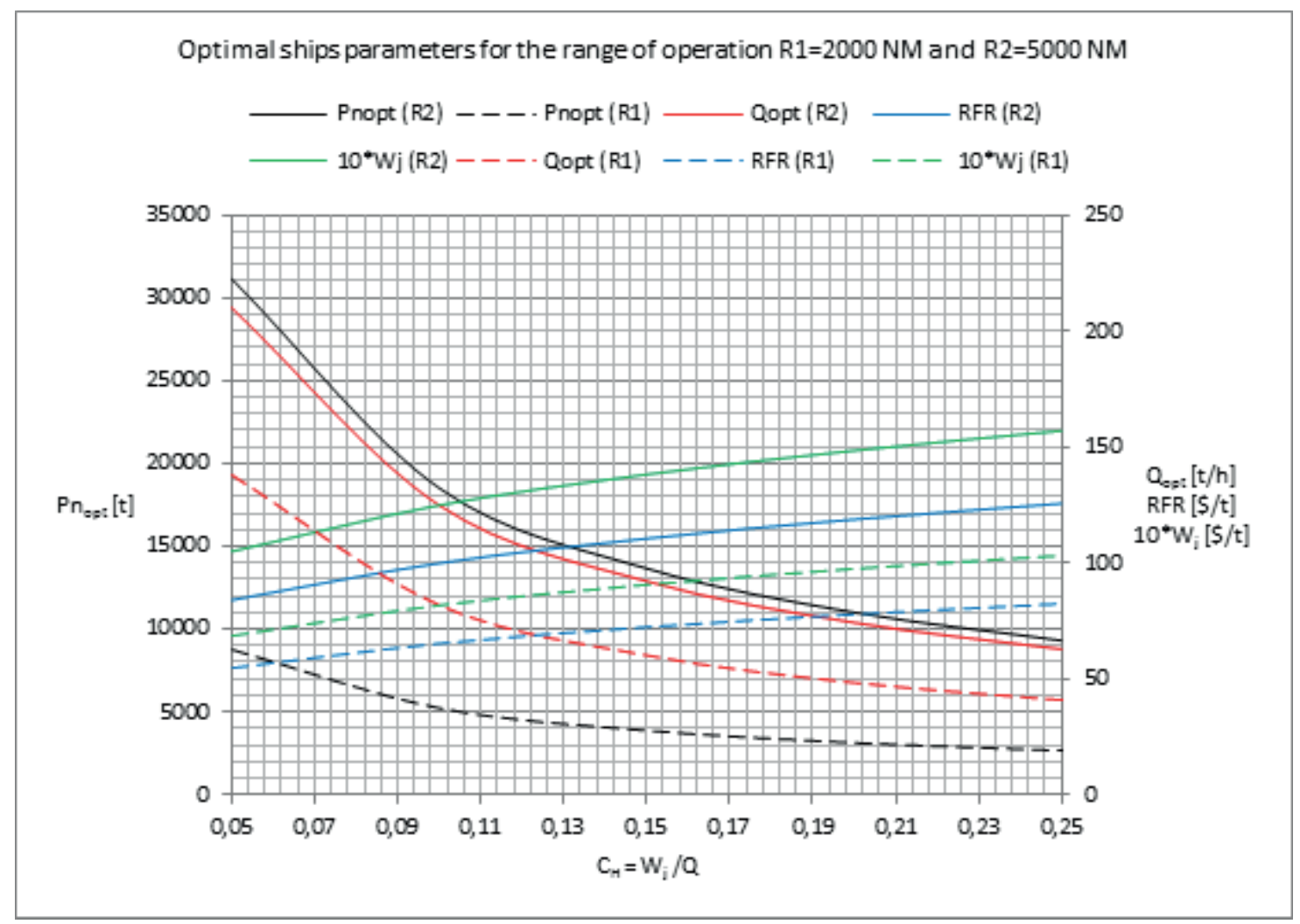

Fig. 1. Example of parametric studies of impact and range of operation on optimal ship's deadweight and required freight rate 
Tab. 1. Example of the use of the presented method to optimize the parameters of a ship on the line Gdańsk-Rio de Janeiro

\begin{tabular}{|c|c|c|c|}
\hline \multicolumn{4}{|c|}{ Example design task } \\
\hline shipowner assumptions & Symbol & Value & U.Measure \\
\hline The speed of the ship & $\mathrm{v}$ & 18,00 & {$[\mathrm{kn}]$} \\
\hline The length of the cruise route & $\mathrm{Ra}$ & 5930 & {$[\mathrm{NM}]$} \\
\hline The average annual inflation rate & $\mathrm{i}$ & 0,03 & {$[-]$} \\
\hline The number of days of operation of the ship in the year & $\mathrm{Zd}$ & 340 & [ day ] \\
\hline The number of hours of operation of the vessel in the year & Zh & 8160 & [hours] \\
\hline The required net rate of return & $\mathrm{r}$ & 0,09 & {$[-]$} \\
\hline Tax rate & $\mathrm{t}$ & 0,19 & {$[-]$} \\
\hline The number of years of operation of the ship & $\mathrm{m}$ & 20 & [ years ] \\
\hline Unit fuel consumption & $\mathrm{Gj}$ & 160 & {$[\mathrm{~g} / \mathrm{kWh}]$} \\
\hline Current fuel price LSMGO & $\mathrm{Cj}$ & 600 & {$[\$ / \mathrm{t}]$} \\
\hline Stopover on the roadstead and in the port & To & 1 & [day/voyage] \\
\hline Stopover on the roadstead and in the port & Toh & 24 & {$[\mathrm{~h} /$ voyage $]$} \\
\hline Coefficient of price for handling efficiency & $\mathrm{C}_{\mathrm{H}}$ & 0,15 & {$[\$ / \mathrm{t}]^{*}[\mathrm{t} / \mathrm{h}]^{-1}$} \\
\hline Parameters of a similar ship & Symbol & Value & U.Measure \\
\hline Carrying capacity of a similar ship & $\mathrm{Pp}$ & 10532 & {$[\mathrm{t}]$} \\
\hline The speed of a similar ship & $\mathrm{vp}$ & 16,5 & {$[\mathrm{kn}]$} \\
\hline Displacement of a similar ship & $\mathrm{D}$ & 14946 & {$[\mathrm{t}]$} \\
\hline Power of a similar vessel & $\mathrm{Ne}$ & 5741 & {$[\mathrm{~kW}]$} \\
\hline Coefficient of Admiralty formula & $\mathrm{Ca}$ & 475 & {$[*]$} \\
\hline Price of a similar ship & $\mathrm{J}$ & 40000000 & {$[\$]$} \\
\hline Utilization factor of displacement & Eta & 0,705 & {$[-]$} \\
\hline Determined auxiliary parameters & Symbol & Value & U.Measure \\
\hline Capacity utilization factor & lamb & 0,9 & {$[-]$} \\
\hline Factor of ship capacity utilization, & eps & 0,9 & {$[-]$} \\
\hline Factor of the cost of service & $\mathrm{mi}$ & 1,1 & {$[-]$} \\
\hline Factor of the cost of purchase of the ship & $\mathrm{Kj}$ & 83250 & {$[*]$} \\
\hline Factor of operating costs & $\mathrm{Kc}$ & 469 & {$[*]$} \\
\hline Factor of handling costs & $\mathrm{Kh}$ & 0,24 & {$[*]$} \\
\hline the cost factor $\mathrm{kg}$ & $\mathrm{Kq}$ & 146880 & {$[*]$} \\
\hline the cost factor $\mathrm{kp}$ & $\mathrm{Kp}$ & 29 & {$[*]$} \\
\hline the cost factor $\mathrm{kr}$ & $\mathrm{Kr}$ & 6362 & {$[*]$} \\
\hline Factor of return of capital & CRF & 0,136 & {$[-]$} \\
\hline Tax correction CRF & CRFT & 0,168 & {$[-]$} \\
\hline Designated technical parameters of the ship & Symbol & Value & U.Measure \\
\hline Optimal dead-weight tonnage & $\mathbf{P n}_{\text {opt }}$ & 17369 & {$[\mathrm{t}]$} \\
\hline Optimal handling performance & $Q_{\text {opt }}$ & 99,7 & {$[\mathrm{t} / \mathrm{h}]$} \\
\hline The minimum freight rate & $\mathbf{R F R}_{\min }$ & 119,69 & {$[\$ / t]$} \\
\hline The unit rate for handling & $\mathbf{W}_{\mathrm{j}}$ & 14,96 & {$[\$ / \mathrm{t}]$} \\
\hline The current capacity of the vessel & $\mathrm{ML}$ & 14069 & {$[\mathrm{t}]$} \\
\hline The current buoyancy of the ship & Displ & 19965 & {$[\mathrm{t}]$} \\
\hline Explanatory power of the engine & Power & 9040 & {$[\mathrm{~kW}]$} \\
\hline Catalogue engine power & $\mathrm{P}$ & 10404 & {$[\mathrm{~kW}]$} \\
\hline A time of 1 cruise & $\operatorname{Tr}$ & 636 & [h] \\
\hline time of the route & $\mathrm{Tm}$ & 329 & {$[\mathrm{~h}]$} \\
\hline Time of loading and unloading & $\mathrm{Tq}$ & 282 & [h] \\
\hline Number of trips per year & LRR & 13 & {$[-]$} \\
\hline Fuel consumption in 1 cruise & ZPR & 477 & {$[\mathrm{t}]$} \\
\hline Design displacement of the ship & Dpr & 24648 & {$[\mathrm{t}]$} \\
\hline Designated economic parameters of the ship & Symbol & Value & U.Measure \\
\hline Invest Cost & Price & 55833579 & {$[\$]$} \\
\hline Annual Cargo Capacity & $\mathrm{ACC}$ & 180631 & {$[\mathrm{t}]$} \\
\hline Annual Cargo Freight & $\mathrm{ACF}$ & 21619473 & {$[\$]$} \\
\hline Annual Fuel Cost & AFC & 4038010 & [\$] \\
\hline Amortization & $\mathrm{A}$ & 2791679 & {$[\$]$} \\
\hline Annual Cargo Handling Cost & $\mathrm{AHC}$ & 5404868 & [\$] \\
\hline Annual Operating Cost & $\mathrm{AOC}$ & 12234557 & [\$] \\
\hline Average Annual Cost & $\mathrm{AAC}$ & 21619473 & {$[\$]$} \\
\hline
\end{tabular}




\section{BIBLIOGRAPHY}

1. Gasparski G. (red.): Metodologia projektowania inżynierskiego. Państwowe Wydawnictwo Naukowe. Warszawa 1973.

2. Bąbiński C.: Elementy nauki o projektowaniu. Warszawa: Wydawnictwa Naukowo-Techniczne 1969.

3. Sójka Z.: Statek Optymalny, Wydawnictwo Morskie, Gdynia 1964.

4. Schneekluth H.: Ship Design for Efficiency and Economy, Butterworth \& Co. Ltd., 1987.

5. Benford H.: Principles of Engineering Economy in Ship Design, Transactions SNAME, 1963.

6. Benford H.: Fundamentals of ship design economics. The University of Michigan. Ann Arbor, 1965.

7. Benford H.: Measures of Merit for Ship Design. The University of Michigan. Ann Arbor, 1968.

8. Buczkowski L.: Kryteria oceny projektu na przykładzie okrętów. Konferencja Metodologii Projektowania, PAN, Warszawa 1973.

9. Perycz E., Sójka Z.: Inwestycje w żegludze morskiej. Wydawnictwo Morskie. Gdańsk 1981.

10. Cotta P.S.: Hull Cost as a Factor in Selecting Ship Speed. Report 091. The University of Michigan, 1970.

11. Michalski J.P.: A method of choosing the service speed of liner trade ships at the stage of establishing owners requirments. Marine Technology Transactions Technika Morska, Polish Academy of Sciences, vol. 10, 1999.

12. Michalski J.P.: Parametric method for evaluating optimal ship deadweight. Polish Maritime Research. 2 (82) 2014.

13. Michalski J.P.: Optimization of Inland Vessels' Route Speed. Marine Technology Transections Technika Morska. Polish Academy of Science. Vol. 15. 2004.

\section{CONTACT WITH THE AUTHOR}

JAN P. MICHALSKI

Faculty of Ocean Engineering and Ship Technology

Gdansk University of Technology

Narutowicza 11/12 Str.

80-233 Gdańsk

POLAND 